PROFESIONALES Y HERRAMIENTAS PARA EL DESARROLLO LOCAL Y SUS SINERGIAS TERRITORIALES. EVALUACIÓN Y PROPUESTAS DE FUTURO IX Coloquio Nacional de Desarrollo Local del GTDL-AGE 

ANTONIO MARTÍNEZ PUCHE, XAVIER AMAT MONTESINOS, ISABEL SANCHO CARBONELL y DANIEL SANCHIZ CASTAÑO (EDS.)

\section{PROFESIONALES Y HERRAMIENTAS PARA EL DESARROLLO LOCAL Y SUS SINERGIAS TERRITORIALES. EVALUACIÓN Y PROPUESTAS DE FUTURO}

IX Coloquio Nacional de Desarrollo Local del GTDL-AGE

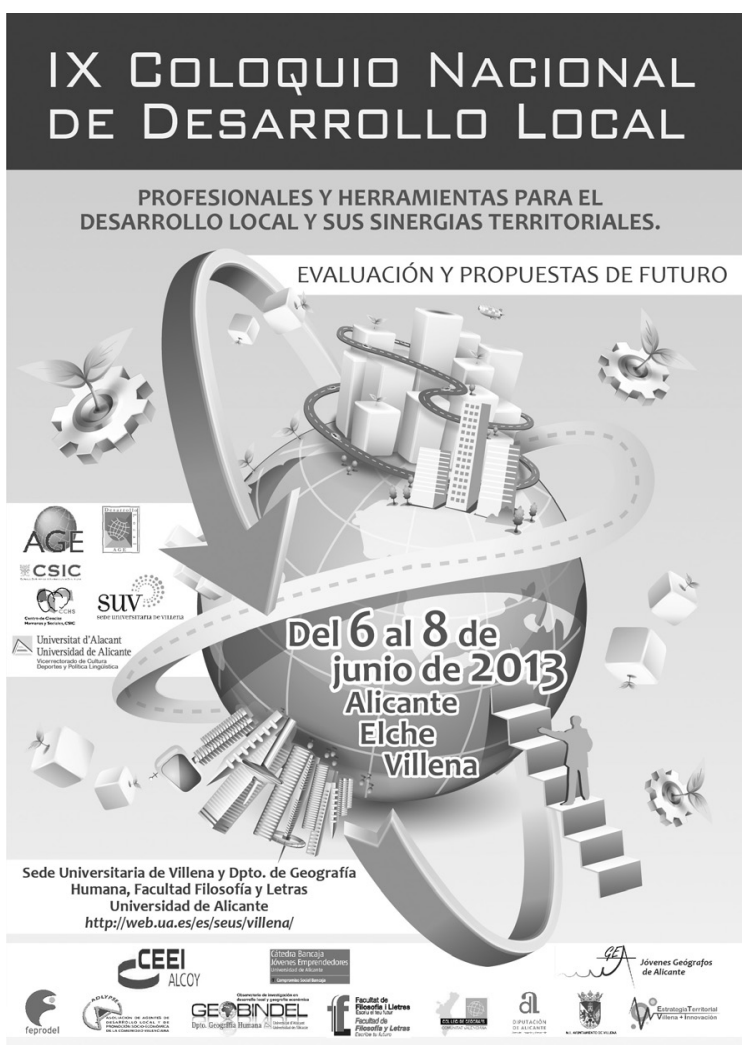


Este libro ha sido examinado y valorado por evaluadores ajenos a la Universidad de Alicante, con el fin de garantizar la calidad científica del mismo.

Publicacions de la Universitat d'Alacant

03690 Sant Vicent del Raspeig

Publicaciones@ua.es

http://publicaciones.ua.es

Telèfon: 965903480

(C) Antonio Martínez Puche, Xavier Amat Montesinos,

Isabel Sancho Carbonell y Daniel Sanchiz Castaño (eds.), 2016

(C) d'aquesta edició: Universitat d'Alacant

ISBN: 978-84-16724-00-0

Dipòsit legal: A 92-2016

Disseny de coberta: candela ink

Composició: Página Maestra (Miguel Ángel Sánchez Hernández)

Impressió i enquadernació: Guada Impresores

\section{unte \\ Unión de Editoriales
Universitarias Españolas \\ WWW.une.es
WWA}

Esta editorial es miembro de la UNE, cosa que garantiza la difusión y comercialización nacional y internacional de sus publicaciones.

Reservados todos los derechos. Cualquier forma de reproducción, distribución, comunicación pública o transformación de esta obra sólo puede ser realizada con la autorización de sus titulares, salvo excepción prevista por la ley. Diríjase a CEDRO (Centro Español de Derechos Repográficos, www.cedro.org) si necesita fotocopias o escanear algún fragmento de esta obra. 


\title{
"SEVILLA, CIUDAD DE ÓPERA": LA IMAGEN MUSICAL COMO HERRAMIENTA DE DINAMIZACIÓN DE LA CULTURA LOCAL
}

\author{
María del Carmen Puche Ruiz. \\ Universidad de Sevilla, Departamento de Geografía Humana \\ mcarmenpucheruiz@gmail.com
}

\section{RESUMEN}

"Sevilla, ciudad de ópera" es un innovador club de producto del Plan Turístico de Sevilla. Su base se asienta sobre la imagen cultural que vincula Sevilla con la tradición operística europea y con sus personajes más conocidos (Figaro, Don Juan, Carmen) y pretende el (re)conocimiento de la ciudad a través de sus óperas.

Este artículo plantea la necesidad de evaluar el calado de la propuesta en la oferta turística sevillana (Consorcio de Turismo, emprendedores del sector cultural), así como la aceptación de los ciudadanos de esa nueva puesta en valor de su patrimonio (muestreo piloto a 30 residentes).

Palabras clave: turismo musical, desarrollo local, patrimonio cultural, imagen cultural.

\section{"SEVILLA, CITY OPERA": THE MUSICAL IMAGE AS A TOOL FOR ENHANCEMENT OF THE LOCAL CULTURE}

\section{AbSTRACT}

"Seville, city of opera" is an innovative Tourism Product Club which promotes the knowledge of the city as an operatic stage, homeland of well-known characters like Figaro, Don Giovanni or Carmen.

This academic article analyses the influence of this tourism product in local entrepreneurs and Tourism Government, as well as the acquiescence of citizens about the new value enhancement actions of Cultural Heritage in the city.

Key words: musical tourism, local development, cultural heritage, cultural branding. 


\section{UN PRODUCTO TURÍSTICO BASADO EN UNA IMAGEN CULTURAL EUROPEA}

Como bien reza en el Manual de Producto Turístico de "Sevilla, ciudad de ópera", la ciudad "es una de las ciudades más cantadas del mundo". Puede que las óperas más representadas en los grandes teatros, las más conocidas y admiradas de todos los tiempos, se localicen en Sevilla. Que el texto diga: "La escena tiene lugar en Sevilla", no es una casualidad, sino fruto y origen de su imagen. Y es que "los libretistas eran los que, con su olfato y su cultura literaria, escudriñaban en los temas que preocupaban en el momento y proponían los argumentos y las localizaciones que según las tendencias y los gustos de la época podían impactar más al público, y así obtener mayor éxito".

Desde el siglo XVII, Sevilla se erige como capital cultural preferida de las élites europeas. Se ha convertido en la ciudad más importante de España y casi de Europa, gracias a su posición dominante como centro comercial de un Imperio donde no se ponía el sol. Aunque casi ninguno de sus máximos exponentes musicales pisara la ciudad, "difícilmente se pueden explicar los más de 100 títulos de tema sevillano si no es por una cierta fijación de determinadas élites europeas por Sevilla". Según los redactores del Manual de Producto, "Sevilla fue más ese ingrediente particular que incitaba a ubicar las más bellas historias de amor, celos, venganza que los creadores podían imaginar, que un escenario real y físico donde situar la acción en cada momento". Esto es debido a la potente imagen cultural que el Arte, la literatura, los viajeros y comerciantes habían creado en torno a la ciudad donde se regulaba el tráfico comercial entre Europa y el Nuevo Mundo.

Sevilla era percibida como un lugar exótico y excéntrico, situado en un extremo del continente europeo, suficientemente alejado de los centros de poder tradicionales para albergar tramas inverosímiles, impensables o prohibidas en cualquier otro escenario. La ciudad acogía todas las ensoñaciones literarias de los viajeros europeos, y el atraso de la sociedad española sirvió para conservar intacto el legado de su imagen; "la decadencia acentuó el atractivo" sobre ellos, que la contemplaban como una "rica ruina" y revitalizaron su mito. La fosilización de esta imagen, que ha perdurado hasta hoy, se basaba en la "conservación de atavismos en estado puro", en una herencia vinculada al Islam que fue muy cara al movimiento romántico. Viajar a España suponía viajar a Oriente sin salir de Europa. Y en tiempos del viajero Richard Ford las fondas españolas serían abominables, pero con el siglo XX y la nueva conciencia de la importancia del turismo como actividad estratégica de imagen y promoción exterior, suponía disfrutar de todo el lujo de Oriente con el confort de Occidente.

Vinculados a la ciudad surgieron los arquetipos de Don Juan, así como los de pillos, pícaros, gitanas y cigarreras, alimentando un sustrato mítico-literario de indudable fascinación. Solamente la creación de la llamada "tetralogía sevillana" ("Don Giovanni", "Il barbiere di Siviglia", "Le nozze di Figaro" y "Carmen") ya sería la envidia de cualquier ciudad del planeta. Pero la ciudad no solo 


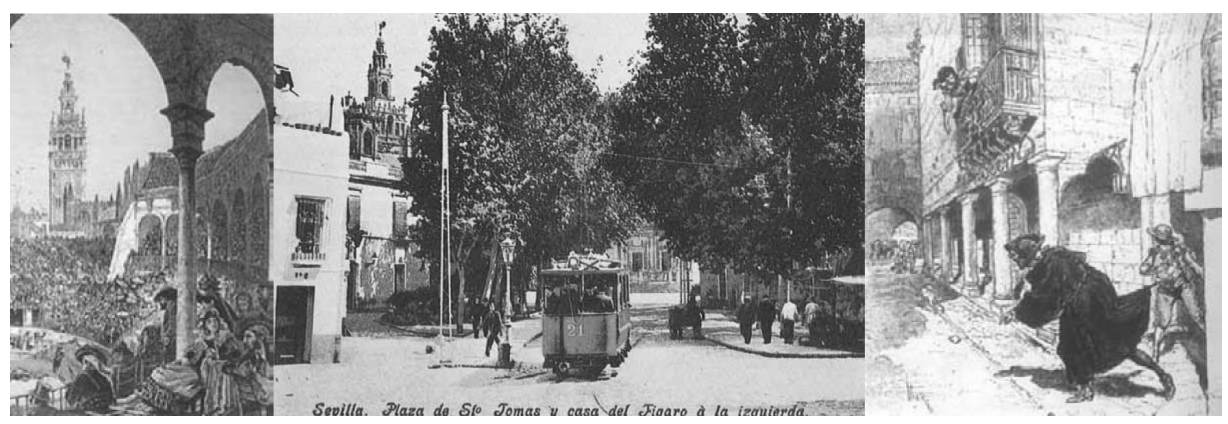

Imágenes 1, 2 y 3: Escenarios de "Carmen" y "El barbero de Sevilla".

Fuente:

es importante por ese abigarrado mosaico de aventuras musicoliterarias: con el fin de renovar su imagen cultural, merece también la pena reivindicar la figura de un personaje tan importante como Manuel García (padre de María Malibrán y Pauline Viardot), compositor, tenor, pedagogo y viajero incansable del siglo XIX, así como el breve periplo turístico de Verdi en Sevilla o la historia de los teatros musicales más importantes de la ciudad.

2. El producto turístico “Sevilla, ciudad de ópera” dentro del Plan Turístico del Consorcio de Turismo de Sevilla

El Plan Turístico de la ciudad de Sevilla, vigente desde 2009, cuenta con la colaboración del $60 \%$ de la Junta de Andalucía y pretende mejorar la competitividad de la ciudad como destino turístico, tomando el río Guadalquivir como eje vertebrador. Promociona 5 productos turísticos, ligados a un Patrimonio hasta ahora ocioso o infrautilizado:

1. El Costurero de la Reina, situado junto al Parque de María Luisa (donde se ha instalado una oficina de turismo dependiente del Consorcio, así como diversas salas expositivas).

2. El Centro de Interpretación del Castillo de San Jorge (ubicado en plena entrada a Triana, donde tuvo su sede la Inquisición Española) y la reinvención del Mercado de Triana como espacio de ocio nocturno (teatro, restauración de calidad) con el fin de revitalizar una zona de imagen tradicionalmente menospreciada y que "el sitio tomara un cariz cultural importante para la ciudad".

3. El Centro de Artesanía de Triana. Se ha planificado la recuperación de la antigua fábrica Cerámica Santa Ana, desde la que partirá una ruta por el barrio que invite a la descongestión del centro histórico y acerque al turista un espacio de tradición basculante y, en ocasiones, degradado, frente al rico conjunto de recursos patrimoniales de la ciudad. 


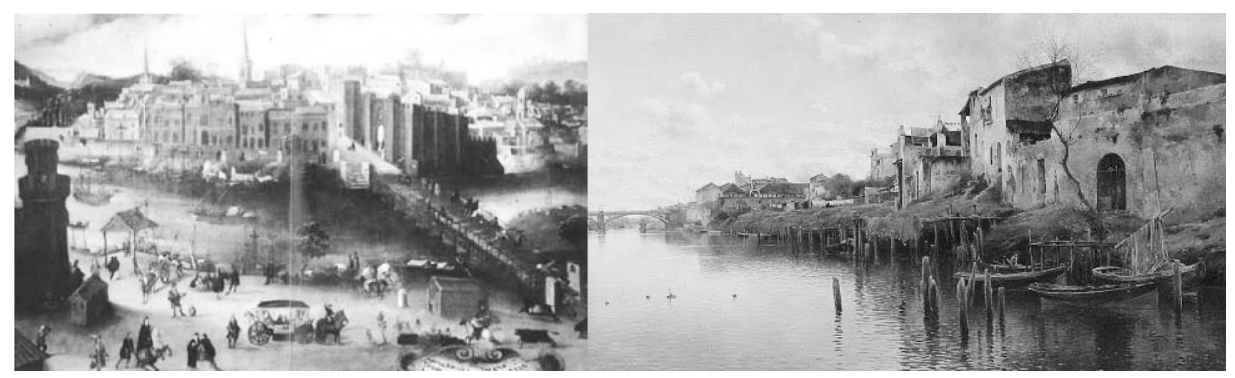

Imágenes 4 y 5: Arrabal de Triana y Castillo de San Jorge.

Fuente: Castillo Ruiz (2008).

4. El río Guadalquivir. Se percibió el desconocimiento de los propios sevillanos de un río que traza su curso como una cicatriz a lo largo de la ciudad, pero con el que se convive dándole la espalda.

Para tratar de acercar el río a los ciudadanos, se ha previsto la recuperación del paseo fluvial del Muelle de Nueva York, mejorando su accesibilidad; la creación del Centro de Atención Integral al Visitante junto a la Torre del Oro; la puesta en marcha del proyecto "Sígueme la corriente", estableciendo acuerdos con empresarios hosteleros ribereños para ofertar lo que se ha denominado "un río con sabor", conectándose a lo largo de su curso con diversos hoteles y restaurantes que lo surcan, el Muelle de las Delicias, el histórico Hotel Alfonso XIII, el Pabellón de la Navegación, el Parque de María Luisa, el Costurero y la Plaza de España; así como el arranque inminente del nuevo producto, "La Sevilla de la Primera Vuelta al Mundo".

5. Sevilla, ciudad de ópera.

Conviene destacar que este último no se contemplaba inicialmente en el Plan Turístico. Sin embargo, desde el Consorcio se vio la oportunidad de crear una poderosa fuente de ventaja competitiva, utilizando como recurso esa imagen de la Sevilla romántica y exótica a la que hacíamos alusión, con el fin de crear un intangible de gran valor, vinculado con el Patrimonio Inmaterial que las más de 140 óperas localizadas en la ciudad han creado.

Se encargó la redacción del Manual de Producto a la consultora "Konecta", complementándose con la publicación del libro de los expertos Ramón Serrera y Andrés Moreno Mengíbar, "La Sevilla de las 100 óperas". Para la configuración del producto se convocó a todo el mundo cultural de la ciudad a través de mesas de trabajo, en las que se diseñaron los itinerarios turísticos que a día de hoy propician un reencuentro con la ciudad en clave de ópera. Participaron en las mismas los siguientes agentes: Junta de Andalucía, Ayuntamiento de Sevilla, Confederación de Empresarios de Sevilla, Universidad de Sevilla, Teatro de la Maestranza, Asociaciones de Guías Turísticos, Amigos de la Ópera de 
Sevilla, Asociación de Agencias de Viajes, Asociación de Hostelería de Sevilla, Asociación de Hoteles de Sevilla y el propio Grupo Konecta.

Como se ha indicado, este Manual de Producto fundamenta la justificación histórica del club de producto en el análisis de publicaciones, tesis doctorales, revistas especializadas y artículos de prensa relacionados con la actividad operística de la ciudad (análisis interno), así como en un somero análisis de otras experiencias (Viena, Salzburgo, Verona, Pesaro, Bayreuth) y un ilustrativo apartado de material gráfico. El Manual se completa con un exhaustivo y valioso inventario de recursos patrimoniales de la ciudad vinculados con su herencia operística y el listado de las óperas identificadas hasta hoy.

Se observa un valioso esfuerzo por parte del Consorcio de Turismo a la hora de recopilar la historia musical de Sevilla, así como sus recursos tangibles e intangibles más importantes. Sin embargo, el análisis externo se demuestra pobre y aventurado. Menciona "propuestas europeas en torno al fenómeno del turismo lírico", con las que contemplar la realización de actuaciones conjuntas y enumera iniciativas y fortalezas de sus competidores (la "Milla de la Música" en Viena, el ambiente musical de Salzburgo), sin percibir la irrealidad de dicho análisis ni llevar a cabo un estudio de mercado relevante. Sus competidores no se encuentran entre estas ciudades europeas, poseedoras de una herencia única que se refleja en sus turistas musicales, sino en ciudades españolas como Santander, A Coruña, Peralada, Madrid o Barcelona, con las que establecer vínculos de cara a la organización de festivales líricos. Conviene ser poco indulgentes en torno a la demanda real de turismo musical en la ciudad.

Los redactores del Manual afirman que "el Teatro de la Maestranza, inaugurado el 2 de mayo de 1991, puso de nuevo a Sevilla en el circuito de las ciudades europeas en las que se podían admirar las producciones operísticas de máxima calidad y lo hizo con un ciclo dedicado a óperas de temática sevillana", pero olvidan que la ciudad, si bien posee los mimbres necesarios para articular este novedoso producto, carece de la experiencia de las ciudades señaladas más arriba, por lo que resulta imposible considerarlas competidoras en el mercado turístico. A nuestro juicio, Sevilla debe potenciar su turismo cultural con esta propuesta y no centrarse exclusivamente en el turista lírico. Al fin y a la postre, se trata de fomentar el conocimiento de personajes universales, de manera didáctica y lúdica, acercando esta disciplina a sus residentes y al gran público, pero en ningún caso la ciudad va a especializarse de la noche a la mañana en el turismo de festivales de música clásica. Resulta llamativo que los redactores del Manual consideren que "no hay iniciativas similares a la nuestra" en todo el espectro europeo estudiado. Se aprecia, por tanto, que la estrategia a desarrollar se encuentra formulada de manera deficiente.

El inventario de recursos, por el contrario, se revela mucho más interesante para el planificador turístico y territorial. Un análisis profundo nos lleva a preguntarnos si ha sido la ciudad la que ha dejado huella en tantas óperas o si ha 
sido la ópera la que, finalmente, ha dejado su huella inmaterial en la ciudad, marcándola para siempre en cada rincón, en cada esquina. Se observa, por tanto, la necesidad de comunicación de este Patrimonio al visitante y al residente. Se localizan 60 puntos diferentes en fichas de inventario tipo, estructurados por materias (13 descartados por su poca importancia histórica), que se desgranan en dos rutas destinadas a interpretar, poner en valor y articular un interesante discurso interpretativo:

- Ruta "La ópera en la Historia de Sevilla".

- Ruta "Sevilla, escenario de ópera".

La única que ha llegado a materializarse es la segunda (con 14 puntos, más convencional que la primera), así como una adicional denominada la "Ruta de los 3 mitos". Sin embargo, la ruta "La ópera en la Historia de Sevilla", que serviría para que el visitante se desviara del centro neurálgico de la misma y se sumergiera en su realidad, de la mano de los teatros y personajes que le han dado su verdadera aura de mito romántico, no se ha contemplado en la planificación final ni en la promoción. Sin embargo, esta ruta es la que permitiría a residentes y turistas dar un paseo diferente por la ciudad y otros centros alejados de sus principales escenarios turísticos, así como conocer a personajes del pasado, con nombres, caras y anécdotas, sin necesidad de convertirse en una ruta especializada para turistas líricos.

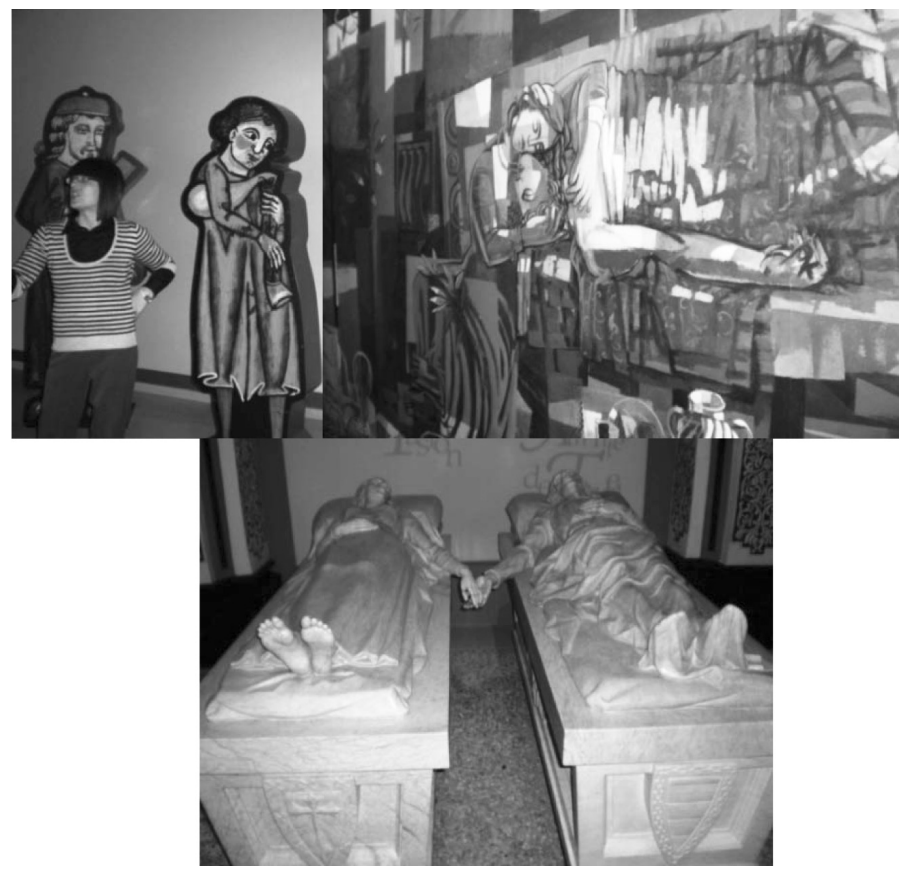

Imágenes 6, 7 y 8: Centro de Interpretación de los Amantes de Teruel.

Fuente: la autora. 
Conviene destacar, igualmente, que en el Manual se contemplaba la apertura de un Centro de Interpretación de "Sevilla, ciudad de ópera" en la Real Fábrica de Tabaco, sede actual de la Universidad. Habría sido una magnífica propuesta ya que, como se afirma, "la mayoría de estos recursos son intangibles y ya no tienen ninguna plasmación en la ciudad". A este respecto, conviene recordar un ejemplo como el del Centro de Interpretación de los Amantes de Teruel. Se trata, a todas luces, de un valioso Patrimonio Intangible de la localidad, sustentado en la leyenda y la existencia de dos momias que la tradición atribuye a estos personajes. Era necesario aportar valor a la experiencia del visitante para que no se limitase a la visita a una oscura iglesia y a la narración de un hecho añejo y polvoriento. Así surgió esta iniciativa, que recoge todas las manifestaciones artísticas surgidas al amparo de la historia de los dos jóvenes amantes y las reúne en un espacio innovador, sugerente y ameno.

Añadido a estos primeros signos de desidia administrativa, hay que hacer notar que la implementación del producto "Sevilla, ciudad de ópera" se encuentra solo en su $2^{\mathrm{a}}$ Anualidad y ya queda patente, sin embargo, la voluntad de cerrar una página de su turismo y seguir abriendo otras temáticas y otros frentes sin solución de continuidad.

\section{TRADICIÓN Y EMPRENDEDURISMO EN TORNO A UNA IMAGEN CULTURAL}

El viajero Augustus Hare comentó sobre el emplazamiento que la tradición popular adjudica a la Casa de Figaro: "Justo detrás del Alcázar está la Plaza de Santo Tomás, donde Figaro el barbero de Sevilla tenía su establecimiento... Es raro que ningún barbero emprendedor se haya instalado ahora aquî".

Y es extraño también que a nadie se le hubiera ocurrido antes explotar tan singular Patrimonio en clave de ópera. Tras un diseño de producto minucioso, la edición de un material interpretativo de primer orden, la creación de una cuidada web y una audioguía compatible con tecnología Android, era de esperar que la puesta en el mercado del producto correspondiese con este alarde de ilusión y medios. Sin embargo, no puede afirmarse que haya sido el caso: una escueta justificación del Producto fechada en enero de 2013 da cuenta de la prisa que tienen sus promotores públicos a la hora de hacer balance de los fondos y mirar hacia proyectos nuevos ("La Sevilla de la $1^{\text {a }}$ Vuelta al Mundo").

"Sevilla, ciudad de ópera" se promovió desde fases muy tempranas a través de famtrips y en la temporada de ópera de Madrid (en 2013 se espera la asistencia de 800 turistas madrileños al estreno de "Rigoletto"); se ha presentado en las más prestigiosas ferias nacionales e internacionales (BIT, WTM, FITUR); su publicidad se ha insertado en medios especializados, intentando que su presencia en eventos operísticos internacionales fuera notable. Por otra parte, se ha concertado un cupo (gracias al convenio de colaboración establecido con el Teatro Maestranza), de aproximadamente unas 3.000-4.000 entradas (se preten- 
de que lleguen a 5.000) por temporada y sin comisiones, a través de la creación de un paquete turístico cuyo adjudicatario fue el turoperador alemán TUI. Sin duda, se advierte que el turista cultural es uno de los más rentables para la ciudad de Sevilla, puesto que pernocta una media de 2,9 noches, cuando la media general es de 1,8; mientras que el gasto medio del turista musical-operístico ronda los $200 € /$ día, cuando lo normal es que sea de $74 €$.

La contratación de estos paquetes compromete a los turistas a una pernoctación mínima de 2 noches, la realización de una visita guiada (a cargo de la empresa "Conocer Sevilla") y se beneficia, por otro lado, de la bienvenida por parte de un receptivo especial (que incluye una carta personalizada y ha tenido muy buena aceptación por parte de los visitantes), así como de las entradas no comisionadas del Teatro de la Maestranza.

El historiador del arte Florencio Quintero se encarga de guiar a los turistas de "Conocer Sevilla" (y a no pocos residentes) a través de los entresijos del Barrio de Santa Cruz, de una forma rigurosa y poética al tiempo. Su colaboración con el Producto "Sevilla, ciudad de ópera" surgió a través del turoperador "HotelBeds" (adscrito a TUI). Este es un turoperador con el que trabajan a menudo, de modo que cuando les propuso presentarse de manera conjunta al concurso convocado por el Consorcio de Turismo de Sevilla para conceder el alojamiento y las visitas guiadas a los recursos operísticos de la ciudad, no se lo pensaron dos veces. De esa sinergia surgió la colaboración y las rutas de ópera que actualmente se realizan en la ciudad (Don Juan en noviembre y Carmen, siempre a petición y según la demanda que exista). Esta no se advierte numerosa, según confiesa el propio Quintero, sin embargo, limitándose las más de las veces a la "demanda cautiva" de los cupos de TUI.

Se ha insertado publicidad de este paquete turístico en la página web de MuchoViaje.com, lo que ha repercutido en 5 millones de visitas a la misma. Esta acción costó en torno a $30.000 €$ por una duración de la campaña de 4 meses. En contrapartida, observamos que en marzo de 2013 se ha redirigido el dominio sevillaesopera.com a la web oficial del Consorcio de Turismo. Donde antes se ofrecía toda la documentación y el material del Producto, ahora se da una rápida y casi renuente visión del mismo. La explicación por parte de sus responsables parece simple: es el Consorcio quien decide la publicidad y toda vez el Producto ha echado a andar, ya se puede integrar en la web común de Turismo. El coste de oportunidad de desaprovechar un medio tan cercano como internet se hace relevante ante este hecho.

Como se muestra, con la comercialización del Producto se ha perseguido que del reparto de los ingresos se beneficie toda la cadena de valor del sector turístico y cultural sevillano, así como añadir valor a la visita del turista con actividades innovadoras que complementen su conocimiento del mito de Sevilla como ciudad inspiradora de personajes y localizaciones operísticas. Según fuentes oficiales, el mantenimiento de un producto como "Sevilla, ciudad de 
ópera" ha permitido la creación de 40 puestos de trabajo directos (27\% de los cuales ha sido en hoteles y $35 \%$ en restaurantes). Con una inversión de aproximadamente 250.000€, se ha logrado una tasa de retorno (según datos del PIB de noviembre a junio) de $1.800 .000 € /$ año.

En la actualidad, existen 92 establecimientos adheridos, a los que se exige que posean, como mínimo, la "Q" de Calidad Turística o una certificación ISO. Estos, normalmente, aparecen también vinculados al producto gastronómico estatal, impulsado por el Instituto de Turismo de España, "Saborea Sevilla". La señalética y los elementos direccionales de los itinerarios ("Ruta de Don Juan", "Ruta de Figaro", "Ruta de Carmen", "Sevilla, escenario de ópera") se diseminan a lo largo de la ciudad, marcando los enclaves estratégicos que el inventario de su manual de producto ha identificado como lugares patrimoniales en la historia de la ópera. Del mismo modo, se pueden seguir las rutas gracias a las más de 40 "huellas" y azulejos-placa (estos últimos, elaborados por Pickman La Cartuja), que ilustran sobre los eventos de tradición literario-operística que allí tuvieron lugar. Esta señalética sorprende al visitante en los lugares más insospechados de su visita y se percibe como descontextualizada y ajena.
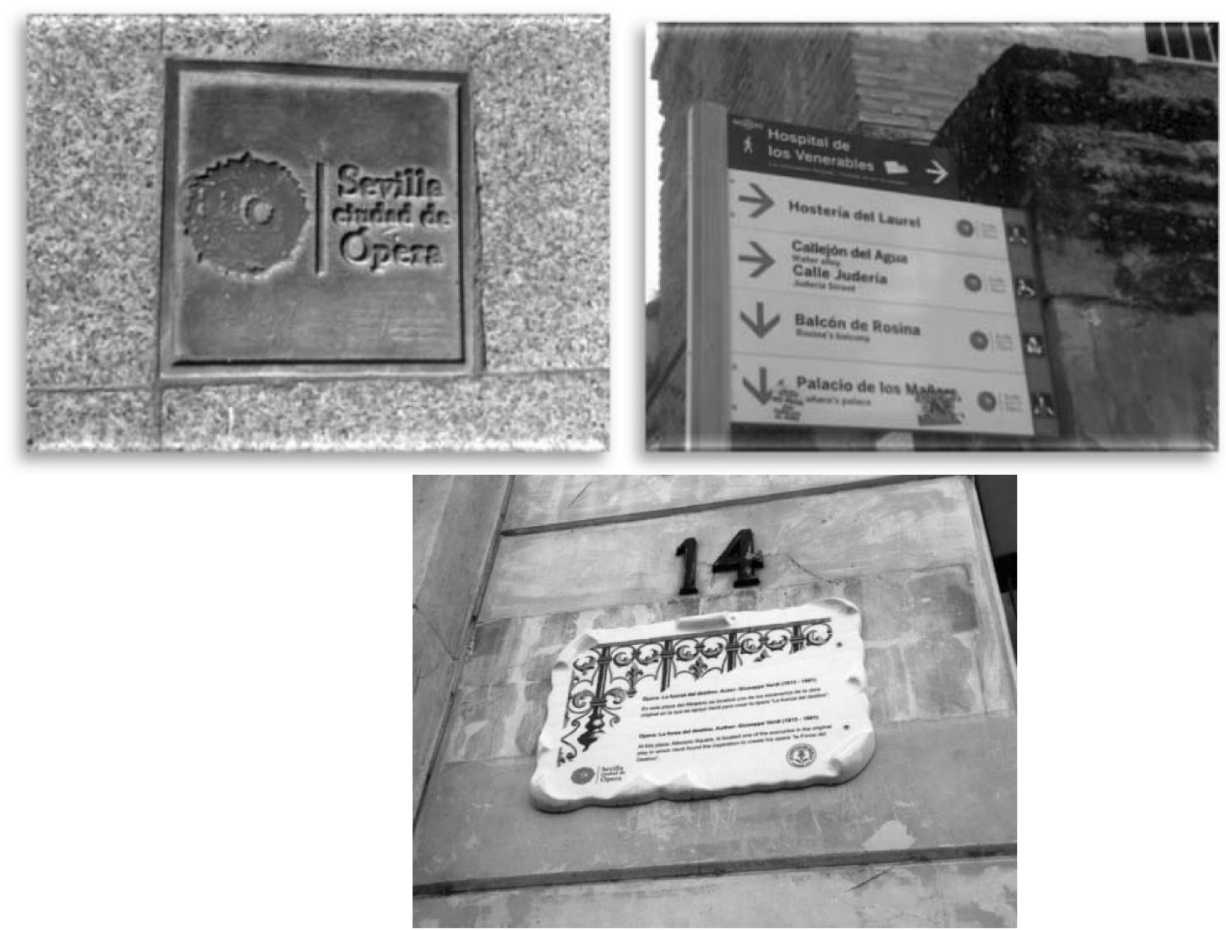

Imágenes 8, 9 y 10: Elementos direccionales e interpretativos del Producto.

Fuente: la autora. 
Signo de una particular desmotivación es que las instituciones turísticas se preocupen solo del aspecto legal (la obtención de una Q de Calidad Turística, como se ha hecho referencia) y, sin embargo, no apoyen decididamente el esfuerzo de emprendedores que, con más pasión que medios y más altruismo que interés monetario, luchan para que la implementación del Producto en el escenario turístico de la ciudad se haga efectiva. Así trabajan los promotores de "Sevilla de Ópera", el primer (y único) tablao lírico de la ciudad: un novedoso concepto en el que el espectador experimenta la ópera a $360^{\circ}$, interactúa con los cantantes y disfruta de la gastronomía sevillana al mismo tiempo. Nada que ver con veladas operísticas de glamour convencional en hoteles de lujo de la ciudad, que recibieron su certificación de adscripción al Producto en su lanzamiento y no ofrecen nada nuevo al turista. Nada que ver con otras propuestas en las que los camareros del restaurante de moda se lanzan a cantar sorpresivamente. Aquí todo el local se convierte en una gran caja escénica temática ambientada en las calles que contemplaron las andanzas de Don Giovanni, Figaro y Carmen, un lugar donde estos personajes pueden tener su casa. Y sus propuestas no dejan de renovarse, fusionándolas con flamenco o música de cámara.

El tablao lírico de "Sevilla de Ópera" se ubica en pleno barrio del Arenal, en el corazón de la ciudad, y aporta una cercanía al cantante que tampoco se encuentra en ofertas como la de la empresa "Engranajes Culturales", que ofrece una visita guiada a la Casa de Pilatos acompañada por un dúo especializado en música antigua. Resulta llamativa la inmediata certificación de esta actividad por parte del Consorcio de Turismo, cuando ninguna de sus actividades se centra en óperas de temática sevillana o en personajes sevillanos.

El gerente de "Sevilla de Ópera", Francisco Oliva, admite que la propuesta no habría sido posible sin la colaboración de su director artístico, el barítono Luciano Miotto, de su conocimiento del mundo lírico y sus artistas, a la hora de proporcionar un producto cultural de calidad inmejorable (aspecto este último al que no están dispuestos a renunciar, por más caro que les cueste). La idea surgió en 2010, cuando Miotto recaló en Sevilla para cantar en el Teatro de la Maestranza "La Traviata". El Producto Turístico del Consorcio estaba siendo introducido en la sociedad sevillana y los promotores de "Sevilla de Ópera" (ayudados por un tercer socio, Antonio León: madrileño con más de 40 años viviendo en Sevilla), decidieron que harían su contribución al mismo. Decididamente, este Producto no podía vivir solo "de piedras y 29 noches de ópera en el Maestranza": ellos propondrían 300 noches al año y unas 48.000 entradas (frente a un cupo que gestionaba en torno a las 3.200 anuales). De este modo, solicitaron su participación activa y su inclusión en el Club de Producto.

El Consorcio de Turismo les ofreció ayuda para encontrar un local adecuado a la propuesta, pero los tres emprendedores no tardaron en darse cuenta de que el proyecto municipal adolecía de "mucha tinta y poca materia". Su propósito, sin embargo, era fundirse con la idea original y tangibilizar el proyecto 
oficial, basado en personajes universales y leyendas difícilmente trasladables a un entorno concreto de la ciudad sin la ayuda de las fuentes originales y su interacción con el visitante. El turista que se sumerge en Sevilla, lo hace con todas las consecuencias: sufre su caos, la estandarización comercial de su centro histórico, la singularidad de su Patrimonio y su idiosincrasia. Sevilla se conoce, principalmente, por los toros, el flamenco y por "Carmen" (Miotto dixit); no tanto por sus Atarazanas ni sus Reales Alcázares.

"Sevilla de Ópera" se emplaza en las tripas de la ciudad: un popular mercado, frente al cual Francisco Oliva posee un bar de tapeo ("La Bottega di Figaro") y la Pensión Arenal. Frente a espectáculos de flamenco en el vecino Paseo de Colón, que no dudan en publicitarse casposamente a los turistas que contemplan la Torre del Oro y el río, "Sevilla de Ópera" acaba de conseguir su adscripción al Club de Producto esta primavera. El mundo artístico de Sevilla los mira con admiración por su impresionante nivel; desde instancias oficiales se avergüenzan de su ubicación junto a un bar que ofrece orgullosamente "pescaíto frito"; y el sector turístico local (AA.VV, guías, hoteles) adora su propuesta, pero pronto se olvida de ella. De diferentes maneras, los promotores locales no cejan en su esfuerzo por revitalizar sus mercados y sus lugares de toda la vida, sin embargo.

No extraña que, ante lo que más arriba hemos denominado como "desidia”, Francisco Oliva actúe por su cuenta: tras esperar más de 6 meses por una autorización municipal que no llega, en breve se promocionarán con un cuadriciclo y dos actores repartiendo publicidad por las calles de Sevilla, caracterizados como "Figaro" y "Carmen". De la mano de la Fundación Cajasol, van a empezar a realizar divulgación escolar, y a partir de mayo comenzarán un nuevo proyecto para acercar los pueblos de Sevilla a la ópera, con autobuses que traerán y llevarán espectadores de municipios cercanos hasta su local del Mercado del Arenal. Francisco Oliva considera que "falla la difusión" y que sería necesario optimizar los recursos que posee el Consorcio para publicitarse en televisión, radio e internet. Y crear un Festival Internacional de Música y Ópera, como ya se hace en Verona. La propuesta parece descabellada a primera vista, pero, con toda la cautela, alguien debería poner la primera piedra para materializar un sueño y una vieja reclamación local: un festival que represente la "tetralogía sevillana" en primavera o verano con cantantes de primer orden. Pero con una propuesta que parta de la base local, no con promotores foráneos de dudosa ética profesional. En la mente de Francisco Oliva surge el proyecto de 2004, que encargó a Michael Ecker la puesta en marcha de un festival que acogería una "Carmen" de ensueño: Angela Gheorghiu y Olga Borodina como protagonistas, Lorin Maazel en el foso y Carlos Saura en la dirección escénica. Aventura que se saldó con un gran escándalo a nivel regional. O el I Festival de Música El Greco, con grandísimas figuras como Renato Bruson o Juan Diego Flórez y que no tuvo continuidad la temporada siguiente. 

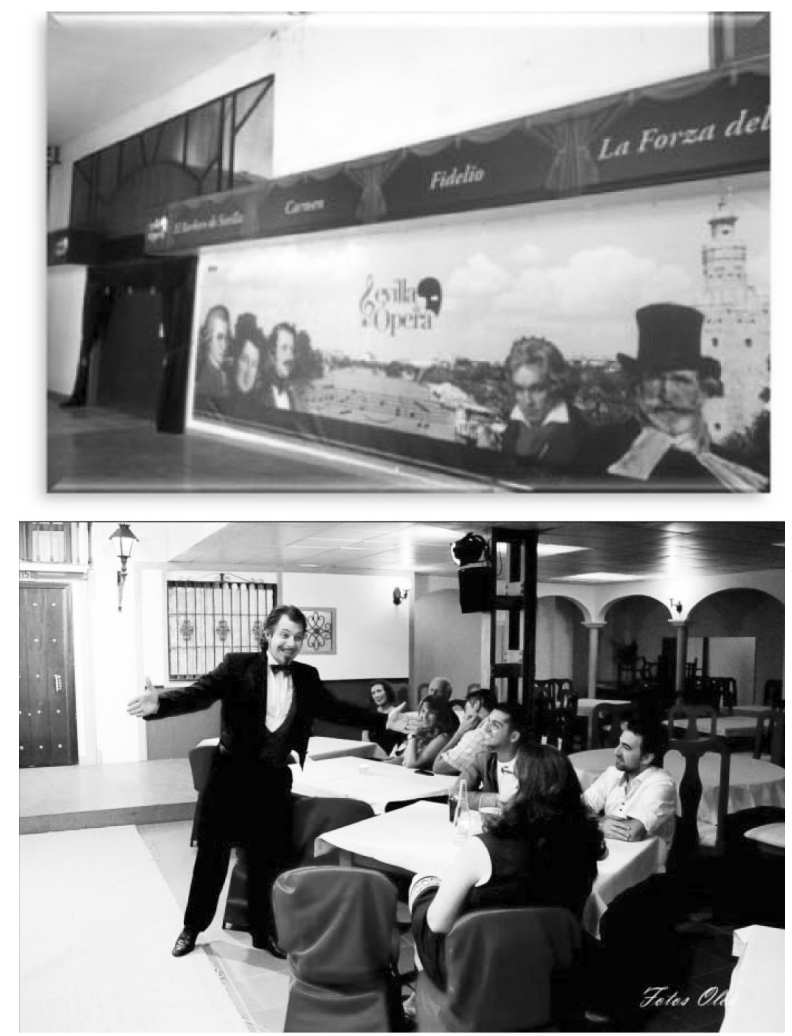

Imágenes 11, 12 y 13: Una experiencia integral: "Sevilla de Ópera".

Fuente: Elaboración propia.

En el caso que nos ocupa, como vemos, no ha sido la implicación empresarial el aspecto más complicado de lograr, sino el apartado de divulgación social. Se ha efectuado "pedagogía al sevillano" (en palabras de su gerencia) en programas y tertulias de televisión, se ha participado en el Día Europeo de la Cultura y en el Día Mundial del Turismo. Uno de los proyectos más ambiciosos al respecto ha sido "Un millón de pasos", en el que se ha tratado de involucrar a la población mayor con el reclamo de mejorar su salud, invitándoles a conocer su Patrimonio desde el punto de vista de la ópera, repartiendo folletos para pacientes hipertensos en los centros de salud con "itinerarios saludables". Otra iniciativa se llevó a cabo en "Halloween" de 2012, tratando de que los sevillanos cambiaran la fiesta de disfraces norteamericana por la tradición de Don Juan en la festividad de Todos los Santos. Así, se dispusieron 3.000 banderolas por toda la ciudad, la música se lanzó a la calle y a los teatros e incluso se fomentó que los colegios representaran la obra. Un proyecto que, pese a sus 12.000€ de inversión, no encontró reflejo en la ciudadanía. Se sigue a la ex- 
pectativa de la oferta de "Carmen" como un personaje de primavera, haciendo hincapié en que con acciones puntuales es imposible que la sensibilización acerca de este Patrimonio intangible y esta imagen de marca tan peculiar se enraíce en la población.

Según la gerencia del Plan Turístico, la Historia de Sevilla queda eclipsada por sus fiestas. Si bien estas aportan colorido, tradición y folclore al turismo, no dejan de transmitir una imagen añeja que se pretende superar a través de su imaginario más ligado a la tradición europea y su imaginario cultural. El éxito de este producto supone un espaldarazo a la imagen de aventura y romanticismo que el Consorcio desea transmitir, gracias a un producto que, además, es limpio, sostenible y tiene como base un recurso intangible fuente de diferenciación para la ciudad.

4. Resultados de la encuestación “Sevilla, ciudad de ópera Para los SevillaNOS"

\section{Cuadro 1. Fuente: Elaboración propia}

1) ¿Sabe qué es "Sevilla, ciudad de ópera"?

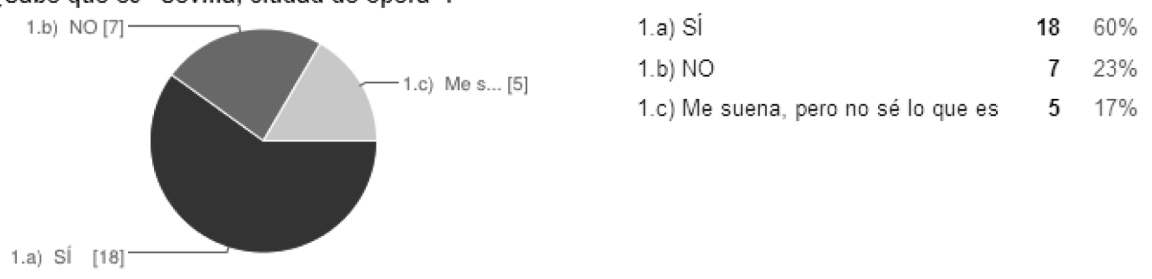

2) ¿Sabría nombrar alguno de los personajes de ópera relacionados con la ciudad?

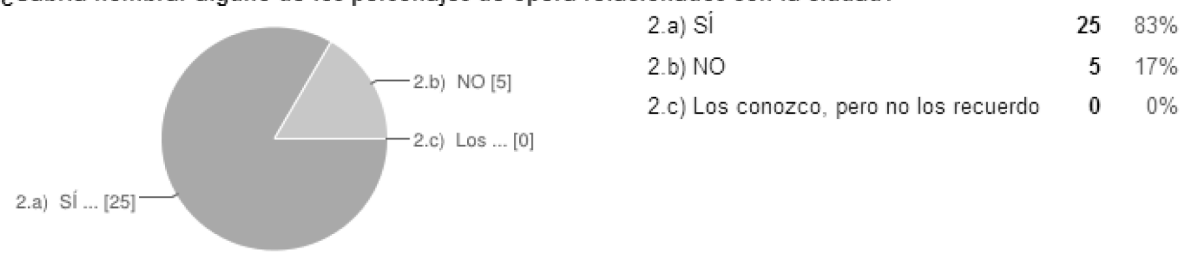

3) ¿Qué significado tienen para usted estos personajes relacionados con Sevilla?

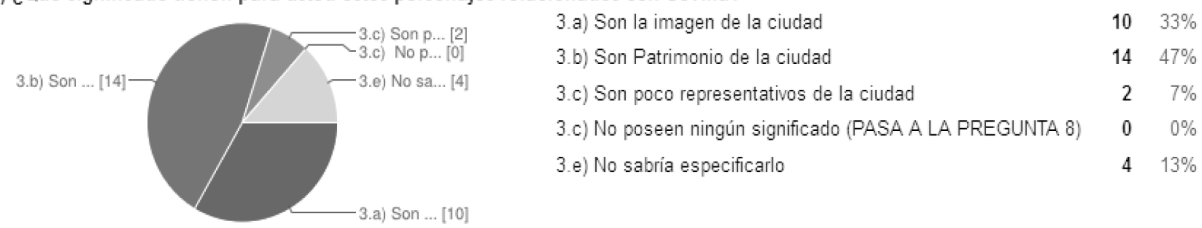


3) ¿Qué significado tienen para usted estos personajes relacionados con Sevilla?
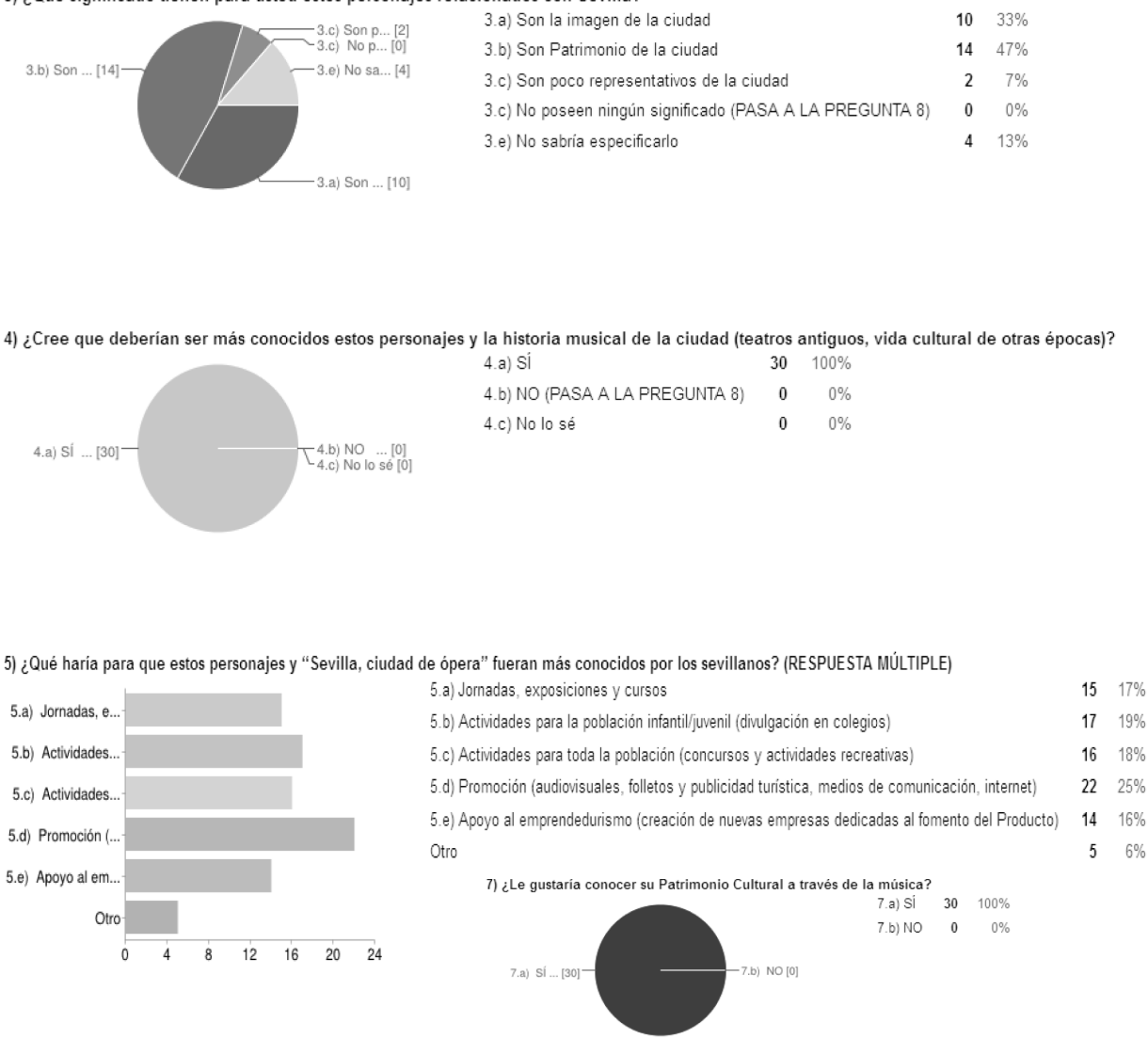

6) ¿Ha realizado alguna visita guiada a la ciudad de Sevilla?

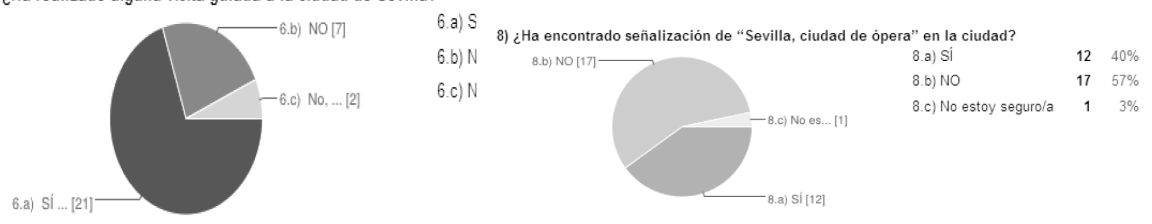

\section{Conclusiones}

Constatado el lujo asiático que supone su material de promoción, podemos afirmar que falta la implementación del producto en el territorio y, sobre todo, lo que el gerente del Plan Turístico de Sevilla denominó con gran acierto: la divulgación al sevillano. Frente a un $60 \%$ de residentes que dice conocer el Producto, a un $17 \%$ le suena y un $23 \%$ confirma su desconocimiento. Para lograr esta divulgación, no es posible basarse solo en acciones puntuales, sino que hay 
que sensibilizar todos los días. En un símil que se podría aplicar a cualquier ser humano, ya que no resulta coherente crear y echar a andar un producto turístico de tal envergadura y, al mismo tiempo, dejarlo desprotegido y abandonado a su suerte: hay que alimentarlo a diario y dotarlo de los elementos para que pueda andar solo y valerse por sí mismo.

Resulta prácticamente imposible realizar una visita guiada a la ciudad de Sevilla sin que, de manera irremediable, surja el mito de Carmen o Don Juan; es decir, todos los turistas conocen siquiera "de oídas" referencias de estos personajes universales, los residentes los consideran obvios y asumidos (un 83\%), todos tararean arias y melodías aunque no sepan su origen. $\mathrm{Y}$ es determinante que no sepan si calificarlos como Patrimonio (un 47\%) o como Imagen en su acepción comercial (un 33\%) o no sepan cuál es su relevancia (un 13\%). Es necesario que la sensibilización en torno a los mismos se lleve a cabo en todas las fases educativas, y la Historia del Patrimonio de la ciudad no se presente a los sevillanos desde los Reales Alcázares solo una vez al año, como ocurrió con la presentación del Club de Producto en 2010 (pese a que cuente con el barítono Carlos Álvarez como inmejorable embajador). Que 1 de cada 4 sevillanos encuestados sienta que falta promoción en torno al Producto o que el 57\% afirme que no ha encontrado señalización interpretativa, no se demuestra como un logro por parte de la difusión oficial.

Por último, conviene resaltar que los sevillanos no se creen este producto turístico. La ciudad se encuentra en un lugar destacado y privilegiado dentro del circuito turístico y su sistema está acostumbrado a vivir de las rentas de su popular imagen, sin contestarla, contrastarla, preguntarse acerca de su veracidad para el turista o cuestionarse su vigencia. Falta pedagogía y rigor en torno a esa imagen y se echa de menos el aprovechamiento de una oportunidad como esta para conseguir proyectar una imagen renovada, falta que la Universidad se involucre con los promotores locales. Sobra desidia institucional y actitudes envanecidas: hay que poner la primera piedra para crear tradición en torno a la imagen musical de la ciudad. Personajes, Patrimonio y Emprendedores. Y sobre todo, faltan promotores de la Administración local que se lo crean.

\section{BIBLIOGRAFÍA}

BERMÚDEZ, A., VIANNEY M. ARBELOA, J., GIRALT A. (2004). Intervención en el patrimonio cultural. Creación y gestión de proyectos. Editorial Síntesis.

BOIRA MAIQUES, J. V., DE LA LLAVE CUEVAS, J. (1987). “Geografía, espacio social e imágenes de marca. El análisis de 'Flor de mayo' de Vicente Blasco Ibáñez”. Saitabi, n. 37, pp. 349-371.

CASTILLO RUIZ, J. (2008). "El entorno de los bienes culturales y el uso público en Centros Históricos", en VV.AA. Uso Público e Interpretación del 
patrimonio natural y cultural (Ponencias de las Jornadas de Uso Público en Espacios Naturales Protegidos y Difusión del Patrimonio Cultural. Sevilla, marzo de 2007). Navarra: Asociación para la Interpretación del Patrimonio DÍEZ TORRIJOS, I., SANCHIS IBOR, C (2007). "Territorio e imagen. La percepción del paisaje de la Huerta de Valencia". Saitabi, n. 57, pp. 63-75. Manual de Producto "Sevilla, Ciudad de Ópera". Consorcio Turístico de la Provincia de Sevilla.

MÉNDEZ ROGRÍGUEZ, L., PLAZA ORELLANA, R., ZOIDO NARANJO, A. (2011). "Viaje a un Oriente europeo. Patrimonio y Turismo en Andalucía (1800-1929)". Sevilla: Centro de Estudios Andaluces y Consejería de Comercio, Turismo y Deporte de Andalucía.

SERRERA, R.M., MORENO MENGÍBAR, A. (2010). "100 óperas de Sevilla". Consorcio Turismo de Sevilla. Área de Planificación Turística. 